\title{
SURDEZ E LINGUAGEM ESCRITA: UM ESTUdO dE CASO
}

\section{DEAFNESS AND WRITTEN LANGUAGE: A CASE OF STUDY}

\section{Ana Cristina GUARINELLO ${ }^{1}$ Giselle MASSI ${ }^{2}$ Ana Paula BERBERIAN ${ }^{3}$}

\begin{abstract}
RESU M 0: partindo do pressuposto de que ao considerar a língua de sinais como a primeira língua do surdo é possível perceber sua inserção no mundo letrado, esse trabalho objetiva analisar produções escritas de um sujeito surdo em momento inicial de apropriação da escrita. Para tanto, concebendo a linguagem como atividade dialógica, como trabal ho social e histórico, constitutivo dos sujeitos e da língua, foram analisados cinco textos produzidos, entre os anos de 1998 e 2002, por um sujeito surdo, reconhecido pela inicial R, em conjunto com a sua fonoaudióloga. Cabeesclarecer quetal profissional, proficienteem língua desinais, atuou como interlocutora e intérprete, priorizando a natureza interativa da linguagem e interferindo nas produções escritas quando solicitada. Durante os anos trabal hados com $\mathrm{R}$, observou-se que ele passou a refletir sobre seus textos e mudou sua postura perante a escrita. $O$ fato de $R$ e a fonoaudiól oga compartilharem a língua de sinais permitiu que ele dividisse suas histórias e experiências, levando-os a registrá-las a partir da língua escrita. Destemodo, R passou a fazer uso da escrita com alternâncias e justaposições entre as duas línguas envolvidas: a língua portuguesa e a língua de sinais. A escrita tornou-se, assim, uma possi bilidade a mais de manifestação da singularidade de R, que passou a reconstruir a história de sua relação com a linguagem.
\end{abstract}

PA LA V RAS-CH A VE: surdez; linguagem escrita; língua brasileira de sinais; educação especial.

A BSTRACT: considering sign language as deaf peoples' first language, it is possible to conceive of the insertion of the deaf into the written world. This work aims to analyze the written productions of a deaf child during his initiation into literacy. We view language as a dialogic activity, as social and historic production, that enables constitution of individuals and their language. Five written texts produced between 1998 and 2002 were analyzed. These were produced by a deaf subject, R, together with his speech and language therapist. It is important to clarify that this professional was fluent in sign language, and she acted as an interpreter and interlocutor, emphasizing language as interaction and interfering in written productions when requested. During the years she worked with $\mathrm{R}$, it was seen that he started to reflect upon his written production and that his attitudes towards writing changed. The fact that $\mathrm{R}$ and his speech and language therapist shared sign language allowed him to talk about his life and experiences; this material was then taken down as written language. Thus, R started to use written language with crossovers and juxtapositions of the two languages he used: Portuguese and sign language. Writting became an added possibility that could reveal his uniqueness as an individual, enabling him to rebuild the history of his relations to language.

KEYWORD S: deafness; written language; Brazilian sign language; special education.

\footnotetext{
${ }^{1}$ Doutora, Docente do Programa de Mestrado e Doutorado em Distúrbios da Comunicação da Universidade Tuiuti do Paraná. Rua M arco Polo, 315, 82820-260, Bairro Alto. Curitiba/ Paraná. E-mail:ana.quarinello@utp.br 2 Doutora, Docente do Programa de Mestrado e Doutorado em Distúrbios da Comunicação da Universidade Tuiuti do Paraná. E-mail: giselle.massi@utp.br

3 Doutora, Docente do Programa de Mestrado e Doutorado em Distúrbios da Comunicação da Universidade Tuiuti do Paraná. E- mail: asilva@utp.br
} 


\section{InTRODUÇÃo}

Vários trabal hos sobre a educação de surdos referem-seàs dificuldades eàs construções lingüísticas atípicas que essa população apresenta no que se refere à modalidade escrita da linguagem (LANE; HOFFMEISTER; BAHAN, 1996; FERN ANDES, 1998; SILVA, 2001; TÉLLEZ; CALDERÓN, 2001; BOTELHO, 2002; GUARIN ELLO, 2007). A tual mente, um número significativo desurdos vem sendo classificado equivocadamente como iletrado pel o fato de fazer uso da escrita sem ter conhecimento da realidadeoral da Língua Portuguesa, nem tampouco da língua de sinais. Contudo, é preciso considerar que esse desconhecimento não se deve a questões individuais, pois, no Brasil, a grande maioria dos surdos adultos não domina a Língua Portuguesa. Além disso, há uma considerável parcela que não teve acesso à língua de sinais, quer seja por motivo de isolamento social, quer seja pel o fato de a família optar por uma escola que não utilize essa língua, o quecausa, além de defasagens escolares, dificuldade e/ ou impedimento quanto à inserção dessas pessoas no mercado de trabalho (GUARINELLO, 2004). Cabe esclarecer que, ainda hojeno Brasil, são poucas as escolas que oferecem uma proposta bilíngüe, na qual a língua de sinais é a principal língua utilizada na escola, a maioria das escolas brasileiras ainda émonolíngüe, ou seja, utiliza somentea Língua Portuguesa.

N essa direção, a compreensão da leitura pelos surdos étradicionalmente referida em diversos trabal hos (FERNA NDES, 1998; GUARINELLO, 2004; TORRES; SANTANA, 2005) como muito abai xo do esperado, apesar deesforços dos educadores e professores de surdos. De forma geral, essas dificuldades com a leitura ea escrita ocorrem porque os surdos não adquirem uma língua, principalmente em famílias ouvintes nas quais nasce um filho surdo eque os pais ouvintes têm dificuldade para comunicar-secom seus filhos surdos. Assim, a interação que deveria acontecer entre pais e filhos muitas vezes não ocorre de forma natural, é forçada, pois os pais de sentem mais confortáveis usando a fala e a audição, e as crianças surdas adquirem linguagem principalmente por meio da visão.

$\mathrm{N}$ as escolas, geralmente, a fala é ensinada formalmente, por meio de um processo que pode durar longos anos e, mesmo assim, a criança surda pode não conseguir adquirir uma fala inteligível. Assim, apesar de essas crianças freqüentarem o ensino formal, não raro a ênfase do processo educacional recai somente sobre a fala (GUARIN ELLO, 2004).

Ainda hoje, algumas escolas especiais para surdos priorizam o desenvolvimento da fala e da audição, como se isso fosse um prérequisito para a aprendizagem da linguagem escrita, ou seja, primeiro éesperado que o surdo fale e depois que aprenda a escrever. N esse sentido, à língua de sinais, fundamental para o desenvolvimento do surdo, acaba não sendo utilizada e o surdo fica em contato apenas com fragmentos da língua oral. Cabe ressal tar que vários estudos demonstram que os surdos, fil hos de pais surdos, estão mais bem preparados para enfrentar a etapa escolar, e que apresentam melhor desempenho na leitura e a escrita, já que foram expostos a uma língua comum entre el es e seus pais, isto é, a 
língua de sinais (SVARTH OLM, 1997; 1999). N o entanto, isso não permiteafirmar queo fato de os surdos nascerem em famílias surdas é suficiente para que tenham um melhor desempenho acadêmico ou no uso da linguagem escrita.

Dentre as pesquisas que apontam as dificuldades dos surdos com a linguagem, salienta-se também a maneira como os profissionais lidam com o sujeito surdo, a surdez e a linguagem. A língua muitas vezes é ensinada por meio de atividades mecânicas e repetitivas, como se fosse um código pronto e acabado. A criança surda só irá aprender a escrever ou a falar quando entrar em contato com adultos usuários e competentes nesta língua e quando tiver oportunidade de participar de atividades lingüísticas significativas. A falta de atividades significativas com a escrita/ fal a impede que os surdos percebam para que servea Língua Portuguesa e, além disso, não conseguem notar as diferenças entrea Língua Portuguesa e a língua de sinais. Somente por meio da interação entre essas modalidades de língua é que o surdo pode tornar-se capaz de apreender as diferenças e usar cada língua de acordo com suas normas. No caso específico da escrita, o surdo deve partir de experiências com a língua quejá domina, em geral a língua desinais, para construir edesenvolver a língua escrita (SVARTH OLM, 1999).

A escola também, geralmente, faz uso de livros didáticos ineficientes, que não permitem que a criança perceba a função do texto. Com as metodologias adotadas tradicionalmente no ensino da língua portuguesa, negou-se aos surdos:

[...] o acesso a práticas lingüísticas significativas que os auxiliassem a perceber o sentido na aprendizagem de uma segunda língua, como conseqüência, as respostas para o fracasso apresentado não foram buscadas nas estratégias inadequadas destinadas ao aprendizado da língua, mas foram justificadas como inerentes à condição da deficiência auditiva e não como possibilidade diferenciada de construção gerada por uma forma de organização lingüísticocognitiva diversa. (FERNANDES, 1998, p.163).

Muitas vezes, os conteúdos escolares que são passados para os surdos costumam privilegiar o ensino de palavras e frases soltas na aprendizagem da escrita, ignorando por completo os aspectos discursivos, a conversação e propondo estratégias, em geral, inadequadas (GUARINELLO, 2005).

É fato que a escola não tem oferecido condições necessárias para que os alunos surdos construam o conhecimento. Assim, na maioria das instituições especiais, os professores não utilizam uma língua compartil hada com seus alunos, ou seja, não dominam a língua de sinais e acabam utilizando uma forma de comunicação bimodal para ensinar. Isto é, usam a fala eal guns sinais concomitantes. Essa estratégia faz com que o surdo ou foque seu ol har para as mãos do professor ou para seus lábios. Se olhar somente para os lábios, compreenderá apenas parte da mensagem; se ol har somente para as mãos, não compreenderá a mensagem da mesma forma, já que verá apenas alguns sinais da língua de sinais desconexos entre si, o que na realidade não forma língua alguma. 
Bernardino (2000), ao avaliar as conseqüências de práticas bimodais, verificou que tal modalidade é ineficiente para os surdos, uma vez que as duas línguas são muito diferentes - uma é auditiva-oral e a outra é viso-espacial. Elas operam sem a gramática da língua de sinais, pois o professor utiliza a combinação da fala com alguns sinais concomitantes. Botelho (2002) também sugere que a dificuldade dos surdos com a linguagem está relacionada ao uso das mesmas práticas pedagógicas vigentes na educação de crianças ouvintes. Além disso, essa autora faz uma crítica ao ensino regular, referindo que a maioria das escolas desconheceo indivíduo surdo eas conseqüências da surdez (ANGELIDES; ARAVI, 2006/2007). Com a inclusão, essas escolas recebem esses alunos com muita preocupação e ressalva, principalmente porque não existe uma língua compartilhada circulando em sala de aula, condição indispensável para que os surdos se tornem letrados. Outra situação, vivida recorrentemente por surdos em escolas regulares, refere-se ao fato de dificuldades do aprendizado, eventualmente, apresentadas pel os mesmos serem compreendidas como decorrência de problemas cognitivos. "Tais formas de pensar são cal cadas em fal sas definições, que arrasam a expectativa em relação às capacidades dos surdos, e reforçam crenças preconceituosas em relação à surdez" (BOTELHO, 2002, p.20).

Alguns estudos, como o de Góes (1999), inserido em uma visão sociointeracionista delinguagem, apresentam os textos deal guns surdos eanal isam suas construções atípicas. Essa autora investigou alunos do ensino supletivo que haviam passado por um longo período de escolarização. Para a realização do seu estudo, envolveu classes desurdos, nas quais os professores seguiam as diretrizes da comunicação total.

$\mathrm{Na}$ análise preliminar de alguns textos produzidos em atividade coletiva, Góes, notou vários desvios das regras de construção do português, tais como: uso inadequado ou omissão de preposições; terminação verbal nãocorrespondente à pessoa do verbo, inconsistência de tempo e modo verbal; flexão inadequada de gênero em adjetivos e artigos; uso incorreto do pronome pessoal do caso oblíquo, entre outros. Em um segundo momento, a autora tomou a escrita como instância dialógica e examinou o quanto às pistas na escrita dos surdos possibilitavam a construção de sentidos pelo leitor, identificando principalmente as características que col ocavam obstácul os ao seu esforço de interpretação. Baseada nos trabalhos de Kock e Travaglia (1990) e Kock (1991), Góes (1999) identificou problemas relativos a aspectos de coesão, principalmente no que concerne à referencialidadeeà progressão temática, visto que estes aspectos tendem a resultar em prejuízos na coerência do texto.

Góes (1999) salientou que as dificuldades dos surdos podem ou não permitir que o leitor encontre pistas para a construção do sentido, já que, em algumas ocorrências, é possível inferir mudanças necessárias à compreensão e, em outras, não há elementos suficientes para a interpretação do sentido. A autora, afirmou, ainda, que é necessário conceder um espaço efetivo à Língua Brasileira 
de Sinais no atendimento educacional do surdo, pois uma de suas hipóteses era que os textos anal isados foram construídos com o apoio parcial em regras da língua de sinais. Porém, para que isso ocorra, é preciso, segundo Góes (1999), encorajar a expansão de projetos quetenham por meta a capacitação dos professores ouvintes, a formação de professores surdos, o incentivo ao trabal ho pedagógico orientado também para o uso da língua de sinais e a ampliação de pesquisas sobre o conhecimento dessa língua.

Góes (1999) pôdeconstatar a interferência da Língua Brasileira deSinais nas redações dos sujeitos surdos. Constatou que os textos escritos dos surdos pautados na língua de sinais não apresentam as mesmas características dos textos deum falante de português, mas deum sujeito falantedesegundalíngua. Também observou que o professor deve perceber que é possível compreender ereconstruir o sentido dos textos por meio da interação com esses sujeitos, seguindo as pistas colocadas nos textos. A autora concluiu que as dificuldades encontradas pelos surdos, com relação à sua escrita, não são um empecilho, mas podem ser uma referência pedagógica para o trabal ho com a segunda língua.

Portanto, é possível entender que mesmo que os surdos não tenham tido a oportunidade de adquirir a língua de sinais precocemente, é nesta língua e não na língua processada pelo canal auditivo-oral que a grande maioria deles se baseia para aprender a falar, ler e escrever. Desta forma, a interferência dos sinais no desenvol vimento da linguagem escrita relaciona-se à aquisição de uma segunda língua. Assim, é imprescindível ressaltar que o surdo precisa desenvolver uma língua efetiva, e, para que isso ocorra, é necessário que as experiências escolares oferecidas a ele privilegiem não apenas a língua de sinais, mas também os aspectos discursivos da escrita, já que esses são fundamentais para que qualquer sujeito, surdo ou ouvinte, seconstitua como falante, leitor eescritor, realizando um trabal ho que proporcione a reflexão sobre o uso da linguagem oral, escrita e da língua de sinais.

Levando em conta essas questões, esse trabalho tem o objetivo de analisar produções escritas de um sujeito surdo em fase inicial de apropriação da escrita.

\section{MÉTOdo}

O caso apresentado faz parte de um corpus col etado em um contexto dínico fonoaudiológico duranteos anos de 1998 a 2002. O sujeito freqüentou sessões de fonoterapia de 45 minutos duas vezes por semana. O material de estudo é constituído por produções escritas de um surdo, coletadas em terapias individuais, nas quais a fonoaudióloga atuou como parceira e investigadora. Cabe esclarecer, que a investigadora é proficiente em língua de sinais.

$\mathrm{R}, 11$ anos, é portador de surdez profunda bilateral, diagnosticada aos dois anos de idade. A partir dos três anos passou a freqüentar uma classe especial 
para surdos dentro de uma escola regular e, nestelocal, adquiriu a língua desinais, comunicando-sebasicamente por meio dessa língua. Além disso, possui excelente leitura orofacial eutiliza-se da fala somente quando solicitado. Em 1995, sua família fez um curso por correspondência para pais de crianças surdas, no Movimento Familiar A Voz do Silêncio (entidade filantrópica destinada aos surdos, local izada em Curitiba).

Sua mãe participou de um curso de Libras e estuda a língua até hoje por meio de apostilas. Tanto a mãe quanto o irmão de $\mathrm{R}$ utilizam a fala e os sinais simultaneamente para se comunicar com ele, o resto da família utiliza-se somente da fala, desconhecendo a língua de sinais.

Durante os anos de 1998 e 1999, R freqüentou a primeira série de uma escola regular. Sua professora dessa instituição rel atou que, apesar deserelacionar muito bem com os colegas ouvintes, eleera bastante desobedienteeindisciplinado. A professora também afirmou que não tinha nenhuma noção sobre surdez esobre os surdos, eque não sabia como trabal har com um surdo em sala de aula. Na sua classe existiam trinta crianças ouvintes e R era o único surdo, sendo assim tinha permissão para sair da sala deaula no momento em quequisesse, já quea professora tinha muitas dificuldades para entender o que el equeria deixando-o agir conforme sua vontade.

Durante as aulas no ensino regular $\mathrm{R}$ costumava copiar os conteúdos dos colegas, não conseguindo compreender as explicações dadas pela professora, que se utilizava somente da língua oral. A professora ainda comentou que todas as crianças já sabiam ler e escrever, com exceção de R que só copiava. R então reprovou a primeira série e continuou por mais um ano na mesma instituição geralmente isolado do resto da turma, já que não entendia as explicações da professora.

Durante os anos de 1997 a 1999, R freqüentou a classe especial no período da tarde, nessas aulas a professora utilizava a fala e os sinais simultaneamente para se comunicar. O trabal ho com a escrita nesta classe iniciouse por meio da escrita de nomes de familiares, desenhos esílabas com / p/ e/ b/ , onomatopéias, números de 1 a 10, vogais, palavras isoladas, separação em sílabas, escrita defrases com verbos específicos, os quais a professora achava quefacilitavam o entendimento dos alunos (EX: Ele tem um avião, ele tem bola, ele tem casa), cópia de textos e frases, escrita e re-escrita de frases simples e estórias. Em 2000, R desligou-se da escola regular e passou a freqüentar somente a classe especial que, a partir de 2001, começou a utilizar somente a Libras durante as aulas.

Durante todos esses anos de atendimento fonoaudiológico, foi priorizado o trabal ho com a escrita. Porém, até 1998, R escrevia apenas palavras sol tas emostrava-se desinteressado com relação à escrita. A legava muita dificuldade e costumava pedir ajuda à terapeuta para ler e escrever. Inicial mente R negava-se a escrever, porém costumava contar várias histórias por meio da língua de sinais, 
a terapeuta então começou a traduzir as histórias da língua desinais para a língua escrita. No momento em que a terapeuta começou a utilizar essa estratégia, R começou a se interessar por essa modalidade de linguagem.

O trabal ho com a linguagem escrita foi subsidiado a partir da concepção da língua como atividade discursiva, sendo a interação privilegiada como lugar em queos sujeitos se constituem como usuários do português na modalidadeescrita. Enfim, consideramos a linguagem enquanto um trabal ho que dá forma ao conteúdo variável de nossas experiências, trabal ho de construção, de retificação do vivido que ao mesmo tempo constitui o sistema simbólico mediante o qual seopera sobre a realidade em que aquele se torna significativo (FRANCHI, 1987). Nessa perspectiva, a língua é resultante desse trabalho coletivo, histórico de uma experiência quese reproduz ese perpetua. O que deriva do social são as regras do jogo da linguagem que se originam na prática com a linguagem. A língua dispõe de múltiplos recursos expressivos que, associados a fatores como o contexto, a situação, a relação entre os interlocutores, as leis conversacionais, etc. fornecerão condições de determinação de um dado enunciado.

Com base nesses princípios, para priorizar a natureza interativa da linguagem, foram utilizados diferentes tipos de textos escritos em jornais, gibis, livros, revistas, apresentando aos sujeitos, poesias, contos, fábulas, receitas, experiências, entrevista. Em todas as sessões procurou-se enfatizar a escrita em contextos significativos, nos quais a pessoa surda fosse capaz de interiorizar a Língua Portuguesa e perceber sua funcional idade.

As atividades real izadas duranteas terapias basearam-seem estratégias, nas quais a terapeuta trazia materiais escritos para a terapia e a partir da leitura desses materiais o paciente escrevia, ou a terapeuta e o paciente discutiam algum tema em língua de sinais e após a discussão o paciente escrevia algo a respeito. É preciso esclarecer queas leituras eram realizadas em conjunto ea terapeuta interferia sempre que solicitada, isto é, quando o surdo não entendia algum vocábulo ou o sentido de uma sentença, era explicado por meio da língua de sinais. Em ambas as estratégias a interferência da terapeuta foi realizada em língua de sinais.

Duranteas atividades com a linguagem escrita foi realizado um trabal ho pela terapeuta queassumiu o papel deinterlocutora eintérpreteda Língua Brasileira de Sinais para o português e vice-versa, interferindo na produção escrita quando solicitada, principal mente com relação aos aspectos lexicais (vocabulário da Língua Portuguesa). Por exemplo, o surdo explicava em sinais o que queria escrever e a terapeuta o auxiliava com uma palavra ou pal avras adequadas em português. Seo surdo não pedisse ajuda, procurou-se não interferir no momento da produção.

Cabe esclarecer que cada produção passava por um processo de construção conjunta do texto, o qual al gumas vezes durava mais do que uma sessão terapêutica. Assim, antes deo surdo escrever uma notícia, o assunto era comentado e discutido e somente depois el e produzia a sua escrita. A pós o término de cada produção, era solicitado que o sujeito rel esse seu texto emodificasse o queachasse 
necessário. Em um último momento, o texto era relido e reescrito em sua versão escrita final, procurando manter-se sempre fiel à idéia original do autor. Durante esse processo de rel eitura e reescrita era perguntado ao surdo por meio da fala ou da língua de sinais, as palavras que não eram compreendidas, ou o que ele quis dizer com determinada frase; o surdo então explicava sua idéia eeram preenchidas as lacunas, modificadas as estruturas truncadas, a pontuação era introduzida, enfim, o texto era aproximado da escrita convencional. O trabalho consistia na (re)construção conjunta de um texto em português, usando as idéias do surdo e o conhecimento de língua da terapeuta. Essa atividadetornou-sefundamental, pois, por meio dessa mediação que o sujeito surdo acaba por progredir no uso que faz de sua escrita.

\section{Resultados e discussões}

O primeiro texto analisado foi produzido por R por meio da língua de sinais e escrito pela terapeuta.

TEXTO 1 (junho/ 98)

O R. viu na televisão o jogo de futebol do Brasil. O Brasil ganhou o jogo de 2 a 1 . O R. desenhou a bandeira do Brasil no caderno. O R. pediu para sua mãe uma bandeira de presente. Um bicho picou o pé e a orelha do R.

Duranteesseepisódio, R contou para a terapeuta sobreo jogo defutebol que tinha assistido durante a Copa do Mundo de 1998. A terapeuta atuou como sua intérprete transcrevendo seus gestos para a escrita. A pós escrever o texto, a terapeuta solicitou que $\mathrm{R}$ procurasse no texto as palavras que já conhecia e desenhasseo significado da palavra sobrea mesma. Na palavra "jogo" enos verbos "ver", "ganhar", "desenhar", "picar" e "pedir" a terapeuta ajudou R explicando o significado das palavras em sinais. A pós desenhar a história, a terapeuta recontoua para que $R$ entendesse seu significado.

Nessa história, é possível perceber que R misturou dois episódios diferentes, pois falou sobre a copa do mundo e sobre uma picada de inseto. Este fato nos mostra que $\mathrm{R}$ ainda não tem noção sobre as narrativas relacionando conteúdos diferentes numa mesma história sem explicá-los.

Durante os anos de 1998 e 1999, a terapeuta trabalhou com atividades de escrita que fossem significativas para R: seqüências lógicas, histórias em quadrinhos, leitura de livros de histórias, escrita de relatos espontâneos, entre outras. Porém, durante todas essas atividades $\mathrm{R}$, em geral, manteve uma atitude passiva pedindo para que a terapeuta escrevesse por ele, satisfazendo-se com esse tipo de escrita. Estes fatos talvez tenham ocorrido exatamente pel a postura que R tinha na escola, já que não precisava escrever, somente copiava a escrita sem compreender o que escrevia elia. 
Somenteem $2000 \mathrm{R}$ passou a interessar-sepela escrita espontânea, esse fato coincidiu com a saída dele do ensino regular e com a utilização somente da Libras no ensino especial. Nesse ano, $R$ passou a pedir para escrever, começou a reconhecer várias pal avras e frases por meio da leitura e a fazer hipóteses sobre a escrita e a solicitar de sua terapeuta que lesse revistas e livros para ele. Contudo, quando era solicitado que tentasse ler sozinho costumava desistir da atividade.

No próximo texto apresentado, a terapeuta e R estavam organizando seqüências de figuras, após a montagem cada um passou a escrever sua própria história.

TEXTO 2 (agosto/ 2000)

O R abriu a porta e viu o trem verde e está brabo com a A.

Durantea produção do texto 2, R pediu ajuda da terapeuta para escrever os verbos "abrir", "ver" e "estar", eas palavras "porta”, "trem" e "brabo". Escreveu sozinho a palavra "verde", porém sem a letra r, quando a terapeuta chamou sua atenção para o queestava faltando, $R$ reconheceu quefaltava tal letra e, em seguida, a acrescentou na palavra. Neste texto, percebe-se que $R$ conseguiu seguir uma seqüência temporal para escrever, porém falta-lhe o vocabulário em Língua Portuguesa para que consiga escrever um texto sem ajuda.

TEXTO 3 (agosto/ 2000)

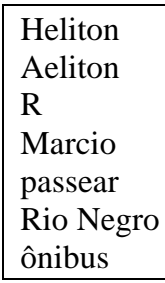

N este texto ocorreu um fato interessante. $\mathrm{R}$ contou para a terapeuta sobre sua viagem com a turma da escola para a cidade de Rio N egro. Depois disso, ele escreveu sobre a viagem. $R$ então escreveu as palavras em forma de lista na ordem de ocorrência dos fatos. Esse fato demonstra que $R$ já tem noção sobre a seqüência dos fatos em uma história, mas ainda Ihe faltam palavras da Língua Portuguesa para juntar esses fatos. Quando questionado pela terapeuta sobre o significado da lista de palavras, $R$ explicou por meio da língua de sinais / $O$ HELITON, O AELITON, O R E O MARCIO FORAM PASSEAR EM RIO NEGRO DE ÔNIBUS/ . Durante essa atividade $R$ pediu ajuda para escrever as palavras "ônibus" e "passear".

No próximo texto analisado $\mathrm{R}$ recebeu um bilhete da namorada da escola e a terapeuta então sugeriu que ele respondesse o bilhete. Este texto foi produzido em novembro de 2000 eserá mostrado um exemplo do trabal ho conjunto 
entreo interlocutor eR, para que o leitor perceba como ocorreram as interferências entre o mediador e a criança.

Como a criança se encontrava em um processo inicial de constituição da escrita, percebem-se várias interferências do adulto mediador, interferências essas que diminuem a medida que os surdos vão desenvolvendo um conhecimento maior da linguagem escrita. O uso somente da/ fala/ será representado entre barras e com letras normais; o uso da / fala + SINAIS/ será sublinhado e as palavras sinal izadas serão apresentadas em letras maiúsculas; o uso somente dos / SIN AIS/ será representado por letras maiúsculas. As palavras escritas serão mostradas entre parênteses e as palavras escritas por meio do / a-l-f-a-b-e-t-o m-a-n-u-a-l/ serão apresentadas por hífens entre as letras. $\mathrm{Na}$ primeira coluna apresenta-se a transcrição e na segunda coluna o texto escrito por R. A baixo se tem a transcrição da fita gravada durante a produção desse texto.

TEXTO 4 (março/ 2001)

\begin{tabular}{|c|c|}
\hline $\begin{array}{l}\text { 1-A: /qual a primeira coisa que escreve?/ } \\
\text { 2-R: aponta para o bilhete e copia o nome da namorada, chama a terapeuta e } \\
\text { fala /eu/ } \\
\text { 3-A: /eu/ } \\
\text { 4-R: /DESCULPAR/ } \\
\text { 5-A: /desculpo, aonde que tá, aqui ô/ e aponta a palavra no bilhete /só que aqui } \\
\text { ô é /po, eu DESCULPO/ } \\
\text { 6-R: escreve (eu desculpo) /AMOR/ } \\
\text { 7-A: lê o que R escreveu, /DESCULPAR VOCÊ/ } \\
\text { 8-R: mostra o que escreveu (eu desculpo vo) } \\
\text { 9-A: lê o que R escreveu /o que é isso aí?// /v-o ta CERTO o que mais?/ } \\
\text { 10-R: /N/ } \\
\text { 11-A: entrega para R o bilhete da namorada, e pede para que ele procure a } \\
\text { palavra (você) /olhe aqui ô/ e aponta a palavra. } \\
\text { 12-R: escreve (você) } \\
\text { 13-A: /MUITO BEM, DEPOIS vai ESCREVER O QUÊ?/ } \\
\text { 14-R: continua escrevendo e mostra seu texto e depois escreve (gosta) } \\
\text { 15-A: /GOSTAR O QUE?/ } \\
\text { 16-R: /MENINA/ e mostra que havia escrito (ela) } \\
\text { 17-A: explica-se que (ela) significa uma outra pessoa e que seria melhor ele } \\
\text { escrever (você) } \\
\text { 18-R: /POR QUÊ?/ } \\
\text { 19-A: repete a } \\
\text { 20-R: faz um comentário sobre a filmadora. /VOCÊ/ escreve (você) } \\
\text { 21-A: /você/ /você O QUE?/ /LEMBRA do VERBO?/ /você pode ser É/ } \\
\text { 22-R: escreve (é) /AMIGA/ e pergunta como escrever a palavra. } \\
\text { 23-A: /você já sabe/ e aponta para o bilhete da menina para que ele encontre a } \\
\text { palavra } \\
\text { 24-R: encontra a palavra (amiga) e escreve } \\
\text { 25-A:/ SÓ? QUERER ESCREVER MAIS O QUE?/ } \\
\text { 26-R: /AMIGA EU GOSTAR/ } \\
\text { 27-A: aponta para o texto de R } \\
\text { 28-R: espera que eu leia seu texto e escreve (gosta você) } \\
\text { 29-A: /O QUE MAIS?/ } \\
\text { 30-R: /EU ELA LÁ/ } \\
\text { 31-A: /mas você já falou duas vezes/ indica o texto /fala o que/ }\end{array}$ & $\begin{array}{l}\text { Suellen } \\
\text { Eu desculpo você, gosta você. } \\
\text { Você é amiga gosta você. } \\
\text { Eu gosta brincar basquete. } \\
\text { Ass R }\end{array}$ \\
\hline
\end{tabular}


31-A: /mas você já falou duas vezes/ indica o texto /fala o que/

32-R: /ELA EU AMIGO LÁ FALAR/ faz com o corpo que queria brincar de

mãe-cola

33-A: /ah, mãe cola/ /VOCÊ QUERER BRINCAR MÃE COLA, VOCÊ

CONVIDAR MENINA JUNTO/

34-R: faz que sim com a cabeça

35-A:/ então escreva aí o nome/

36-R:/EU GOSTO BRINCAR/ e escreve (eu gosta brincar)

37-A: /MUITO BEM/

38-R: mostra seu texto /ESCONDER/ faz alguns sinais

39-A: não entende o que ele quis dizer

40-A: / eu NÃO SEI o NOME/

41-R: /BASQUETE/

42-A: entende e escreve /b-a-s-q-u-e-t-e/

43-R: escreve (basquete) e mostra para a terapeuta

44-A: /ACABOU?/

45-R: /SIM/

46-A: /como é que você vai ASSINAR?/

47-R: escreve seu nome.

Durante a produção destetexto, nota-se que R, apesar de pedir muitas vezes ajuda, principalmente com relação ao português, parece que, aos poucos, está construindo um novo modelo detexto escrito. A esserespeito pode-se recorrer ao trabal ho de Koch (1995), quando afirma que a criança na fase inicial da escrita transpõe para seu texto procedimentos que está acostumada a usar na fala. No caso de R, nota-se que ele al gumas vezes transpõe para o texto os procedimentos que usa na língua de sinais, já que conta a história toda nessa língua e parece apenas traduzir os sinais para as pal avras escritas em português, sem se preocupar com as convenções da Língua Portuguesa. Um exemplo disso pôde ser notado na frase / eu gosta brincar basquete/ , na qual R não utiliza nenhuma preposição e nem a forma convencional do tempo verbal. É por meio da intervenção que ele começa a produzir um texto escrito com significado e funcionalidade.

Durante toda a construção do texto escrito, é possível notar o "adulto letrado, constituindo-se num OUTRO para o SUJEITO/ criança, confrontando-a com a idéia de que a escrita veicula sentidos e não é simples seqüência de letras desenhadas ao acaso, desencadeia a busca de sentidos" (MAYRINK-SABINSON, 1997, p.47). É por meio do diálogo que se encontraram indícios de que o que o interlocutor diz ou fala tem repercussões no que $\mathrm{R}$ diz e fala e vice-versa.

Percebe-se nessa construção que, em alguns casos, foi feita uma interferência direta, por meio de observações ou recomendações, como, por exemplo: linha 1, quando foi perguntado para R / qual a primeira coisa que ele deveria escrever/ ; na linha 13, em que se perguntou / edepois vai escrever o que/ ; nalinha 15, em queR havia escrito / gosto/ efoi perguntado / do queelegostava/ ; na linha 21, em que foi sugerido que R colocasse o verbo / él no seu enunciado. Em outros casos, nota-se uma recomendação mais ampla para que $R$ reescreva, por exemplo: nas linhas 4 e 5, nas quais R queria escrever / desculpa/ esugeriu-se 
que ele procurasse no bilhete da namorada a pal avra / desculpar/ , então pediu-se para que ele mudasse a palavra para / desculpo/ e nas linhas 16 e 17, em que R havia escrito / ela/ e foi sugerido que ele mudasse para / vocêl .

Conforme comentado anteriormente, antes de iniciar um trabalho lingüístico significativo, a escrita de R evidenciava o tipo de escrita geralmente utilizada pela escola, ou seja, frases sol tas e descontextualizadas. Percebe-se que $\mathrm{R}$, até então, não utilizava elementos de ligação entre as frases, iniciando novas frases da mesma forma e preocupando-se com fatores bastante considerados pela escola como a pontuação e o uso de letras maiúsculas e minúsculas. Contudo, faltam-Ihe palavras, verbos, preposições, ou seja, o vocabulário da Língua Portuguesa, coisas que lhe sobram quando conta uma história em língua de sinais.

No último texto analisado produzido em setembro de 2002, R, inicialmente, leu uma história e depois foi sugerido que ele escrevesse sobre a mesma.

TEXTO 5 (setembro/ 2002)

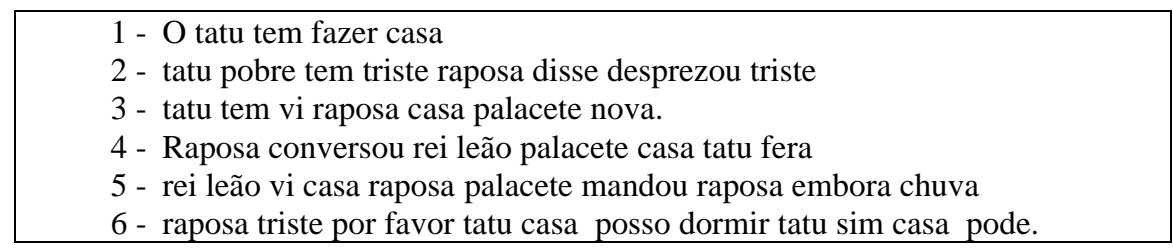

Nesse texto nota-se, novamente, que $\mathrm{R}$ tem dificuldade no uso dos verbos em português, já que usou somente duas formas verbais / tem e vi/ no texto todo. Quanto aos outros verbos utilizados, como / disse/ , na linha 2, / conversou/ , na linha 4, / mandou/ , na linha 5 e / posso/ e/ pode/ , na linha 6, R fez o sinal esolicitou ajuda para escrever, sendo queas terminações verbais foram colocadas pela terapeuta. O tópico do texto égarantido por um tema constante, ou seja, todo texto refere-seà seqüência de uma mesma história. Também se constatam os sucessivos encadeamentos por justaposição, principalmente marcados pela pontuação; porém não se nota a conexão por meio de articuladores textuais.

Para que esse texto fosse percebido como coerente e para que o sentido fosse estabelecido foi necessário que se ativassem conhecimentos de mundo e delíngua. Assim, a terapeuta pode fazer inferências na escrita de R e construir o sentido do texto.

\section{Conclusões}

Analisando os textos de $\mathrm{R}$, é possível afirmar que os elementos que faltam em seus textos, tais como, preposições, artigos, conjunções eal guns verbos, são, em sua maioria, exatamenteaqueles elementos queinexistem ou semanifestam de outra maneira na língua desinais, sua primeira língua. Segundo Richter (2000), 
na aprendizagem de segunda língua (L2), as crianças que se encontram nos primeiros momentos de aquisição, comumente simplificam suas estratégias de planejamento e execução, emitindo apenas um número mínimo deconstituintes, o que faz com que hajam lacunas no seu enunciado, ou seja, uma simplificação semântica e lingüística da mensagem. Pode ocorrer, assim, omissão de palavras, de elementos coesivos etc., e isso, além de ser bastante comum na aprendizagem da primeira língua (L1), também é muito observado quando qualquer aprendiz está adquirindo uma segunda língua. Essa hipótese pode explicar o uso queR está fazendo da linguagem escrita.

Outro fator relevantena escrita deR refere-seà importância da interação com adultos conhecedores da língua de sinais, pois são os adultos que responderão às pistas das crianças de acordo com seu nível de linguagem. Foi por meio da interação com o outro que R pôde construir hipóteses sobre a linguagem escrita e negociar sentidos. Essa negociação se deu pela confirmação de pedidos de esclarecimento, clarificação, repetição, contestação e questionamentos e é consi derada a condição necessária para o domínio da língua escrita.

Durante os anos trabalhados com $\mathrm{R}$, observou-se que ele passou a refletir sobre seus textos e mudou sua postura perante a escrita. Inicialmente, $R$ negava-se a escrever, queria apenas contar seus textos por meio da língua desinais, eque a terapeuta os escrevesse. A os poucos, com a atividadetextual partilhada, $R$ foi perdendo o receio da escrita e começou a fazer hipóteses, a planejar seu texto e junto com um adulto a construir suas histórias. É óbvio que ele ainda não domina todos os aspectos formais e o conjunto de convenções que regulamentam o uso social da escrita, mas, por meio da mediação do adulto, provedor da escrita ecriador de oportunidades para que esses aspectos se tornem evidentes, $R$ foi capaz de aceitar o desafio de escrever e produzir textos com coerência, criatividade e sem medo de errar. Pois, apesar de Ihe faltarem palavras na Língua Portuguesa, não Ihe faltava o que dizer, apenas como dizer. O fato deR ea terapeuta compartilharem a língua de sinais permitiu que ele dividisse suas histórias e experiências, levandoos a registrar essas histórias a partir da língua escrita. Deste modo, $\mathrm{R}$ passou a fazer uso da escrita com alternâncias e justaposições entre as duas línguas envolvidas: a Língua Portuguesa e a língua de sinais. A escrita tornou-se, assim, um espaço a mais de manifestação de sua singularidade, e R passou, então, a reconstruir a história de sua relação com a linguagem.

\section{Referências}

ANGELIDES, P.; ARAVI, C. A comparative perspective on the experiences of deaf and hard of hearing individuals as students at mainstream and special schools. A merican A nnals of the D eaf, Washington, v. 151, n. 5, p. 476-485, 2006/ 2007.

BERNARDINO, E. L. A bsurdo ou logic: os surdos e sua produção lingüística. Belo H orizonte: Ed. Profetizando a vida, 2000. 
BOTELHO, P. Linguagem e letramento na educação dos surdos. Ideologias e práticas pedagógicas. Bel o Horizonte: A utêntica, 2002.

FERN ANDES, S. F. Surdez elinguagens: épossível o diálogo entreas diferenças?. 1998. 216f. Dissertação (M estrado em Estudos Lingüísticos) - UniversidadeFederal do Paraná, Curitiba. FRAN CHI, C. Criatividade e Gramática. Trabalhos em lingüística aplicada, Campinas: IEL/ UNICAMP, n. 9, p. 5-45, 1987.

GÓES, M. C. R. Linguagem, surdez e educação. 2.ed. Campinas: Autores A ssociados, 1999.

GUARINELLO, A. C. 0 papel do outro no processo de construção da produção da escrita de sujeitos surdos. 2004. 207f. Tese (Doutorado em Estudos Lingüísticos) - Programa de Pós Graduação em Letras, UniversidadeFederal do Paraná, Curitiba.

GUARINELLO, A.C. As produções escritas de sujeitos surdos. R evista Letras, Curitiba, $n$. 65, p. 135-151, 2005.

GUARINELLO, A. C. 0 papel do outro na escrita desujeitos surdos. São Paulo: Plexus, 2007. KOCH, I.G.V. A coesão textual. São Paulo: Editora Contexto, 1991.

KOCH , I. G. V. A quisição da escrita etextualidade.Caderno deEstudos Lingüísticos, Campinas, n.29, p.109-117, 1995.

KOCH, I.G.V.; TRA VA GLIA , L.C. Coerência textual. São Paulo: Editora Contexto, 1990.

LANE, H.; HOFFMEISTER, R.; BAHAN, B.A journey into the deaf world. San Diego: Dawnsign Press, 1996.

MAYRINK-SABINSON, M. L. Um evento singular. In: ABAURRE, M. B.; FIAD, R. S.; MAYRINK-SABINSON, M. L. (Org.). Cen as de aquisição da escrita: o sujeito eo trabal ho com o texto. Campinas: Associação de Leitura do Brasil (ALB), 1997.

RICHTER, M. G. Ensino do português el nteratividade. Santa M aria: UFSM, 2000.

SILVA, M. P. M. A construção desentidos na escrita do al uno surdo. São Paulo: Plexus Editora, 2001.

SVARTHOLM, K. La educación bilíngüe de los sordos: princípios básicos. Revista El Bilingüismo de los Sordos. Santa Fé de Bogotá, v. 1, n. 3, p. 30-45, 1997.

. Bilingüismo dos surdos. In: SKLIAR, C. et al . A tualidade da educação bilíngüe. Porto Alegre: Mediação, 1999. v. 2.

TÉLLEZ, L. R.; CALDERÓN, V. P. Una experiencia en el desarrollo de la segunda lengua. In: CONGRESSO LATINOAMERICANO DE EDUCACIÓN BILINGÜE/ BICULTURAL PARA SORDOS, 6, 2001, Santiago, Chile. A nais..., Santiago, Chile.

TORRES, M. S.; SANTANA, H. R. Reading levels of Spanish deaf students. A merican A nnals of the D eaf, W ashington, v. 150, n. 4, p. 379-387, 2005.

Recebido em 23/ 04/ 07

Reformulado em 28/ 06/ 07

A provado em 30/ 08/ 07 